\title{
FIBULA-BROOCH WITH PENDANTS FROM THE BARROW STUDIED IN THE NORTHERN SURROUNDING AREAS OF CHERKESSK
}

\author{
Yury A. Prokopenko \\ North-Caucasus Federal University Humanities Institute, Stavropol, Russian Federation
}

\begin{abstract}
Svetlana L. Kravtsova
The G.N. Prozritelev and G.K. Prave Stavropol State History, Culture and Natural Landscape Reserve Museum, Stavropol, Russian Federation
\end{abstract}

\begin{abstract}
Introduction. The article is devoted to characterizing the decorative features of the fibulabrooch discovered during the study of the mound in the northern surrounding areas of Cherkessk (territory of the Republic of Karachay-Cherkessia) and stored in the collection of the Stavropol State Museum. The aim of the publication is to introduce the poorly known scientific material into scientific use. A full set of illustrations and accurate measurements will further avoid confusion with the description of the specific artifact (in existing publications there are no drawings; conclusions are based only on photos). Explanations relate to the history of the brooch and details of its decoration. Methods. The comparative typological method is used as a working one. It is based on the classification by material, processing method, form, ornamentation, as well as identifying and studying types of brooches with pendants. The comparative analysis of the decor of the brooch from the Stavropol museum and similar brooches with pendants found in the western part of the North Caucasus shows the variety of polychrome decoration production technologies in the region in the $3^{\text {rd }}-1^{\text {st }}$ centuries BC: preserving the traditions of Bosporan jewelry art; distribution of the elements of Colchian toreutics. Analysis. The paper considers design features of brooches from the Stavropol museum and monuments of the Western Ciscaucasia: details of zoomorphic figurines; characteristics of caste design; wire inlay; form and features of enamel inserts; character of pendant weaving and features of the design of suspended discs. Results. In the production of hollow zoomorphic images of the $3^{\text {rd }}-1^{\text {st }}$ century BC there were two lines of development: 1) simplified modeling of figurines modeled on the pattern of Colchian products of the $5^{\text {th }}-4^{\text {th }}$ centuries BC (Psenafa and others); 2) continuation of the tradition of producing jewelry with enamel (brooch from the mound in the land of Rodina state farm). In the first case, the simplicity and negligence of execution evidence established local production of imitations of Colchian images. In the second case, elegance of images and refinement of execution emphasize the creation of brooches of Karachay-Cherkessia in one of the centers of Bosporus toreutics which was under the influence of Colchian jewelry.
\end{abstract}

Key words: fibula-brooch, disc-shaped pendants, hollow figures, filigree, Late Hellenistic period, toreutics.

Citation. Prokopenko Yu.A., Kravtsova S.L. Fibula-Brooch with Pendants from the Barrow Studied in the Northern Surrounding Areas of Cherkessk. Vestnik Volgogradskogo gosudarstvennogo universiteta. Seriya 4. Istoriya. Regionovedenie. Mezhdunarodnye otnosheniya [Science Journal of Volgograd State University. History. Area Studies. International Relations], 2019, vol. 24, no. 5, pp. 19-33. (in Russian). DOI: https://doi.org/10.15688/ jvolsu4.2019.5.2

ФИБУЛА-БРОШЬ С ПРИВЕСКАМИ ИЗ КУРГАНА, ИССЛЕДОВАННОГО В СЕВЕРНЫХ ОКРЕСТНОСТЯХ ГОРОДА ЧЕРКЕССКА

\section{Юрий Анатольевич Прокопенко}

Гуманитарный институт Северо-Кавказского федерального университета, г. Ставрополь, Российская Федерация 


\section{АРХЕОЛОГИЯ ВОСТОЧНО-ЕВРОПЕЙСКИХ СТЕПЕЙ}

\section{Светлана Леонидовна Кравцова}

Ставропольский государственный историко-культурный и природно-ландшафтный музей-заповедник им. Г.Н. Прозрителева и Г.К. Праве, г. Ставрополь, Российская Федерация

Аннотация. Введение. Статья посвящена характеристике декоративных особенностей фибулы-броши, обнаруженной во время исследования кургана в северных окрестностях г. Черкесска (территория Карачаево-Черкесской Республики) и хранящейся в собрании Ставропольского государственного музея-заповедника. Целью публикации является ввод в научный оборот малоизвестного исследователям научного материала. Полный набор иллюстраций и точные замеры позволят в дальнейшем избежать путаницы с описанием артефакта. В существующих публикациях отсутствуют рисунки, а выводы строятся только на основании фотографии. Пояснения касаются легенды происхождения истории броши и деталей ее декорирования. Методbl. В качестве рабочего использован сравнительно-типологический метод. Он основан на классификации по материалу, способу обработки, форме, орнаменту, а также на выделении и исследовании типов брошей с привесками. Сравнительный анализ декора украшения из Ставропольского музея и подобных брошей с привесками, обнаруженных в западной части Северного Кавказа, свидетельствует о разнообразии технологий производства полихромных украшений в регионе в III-I вв. до н. э.: сохранение традиций боспорского ювелирного искусства; распространение элементов колхидского «златокузнечества». Анализ. Рассматривались особенности оформления брошей из Ставропольского музея и памятников Западного Предкавказья: детали зооморфных фигурок; особенности оформления каста; проволочный декор; форма и особенности эмалевых вставок; характер плетения привесок и особенности оформления привешенных дисков. Резульmambl. В производстве полых зооморфных изображений III-I вв. до н. э. наблюдаются две линии развития: 1) упрощенная моделировка фигурок по образцу колхидских изделий V-IV вв. до н. э. (Псенафа и другие); 2) продолжение традиции производства украшений с эмалью (брошь из кургана на земле совхоза Родина). Если в первом случае простота и небрежность исполнения свидетельствуют о налаженном местном производстве подражаний колхидским изображениям, то во втором изящность изображений и изысканность исполнения подчеркивают создание броши из Карачаево-Черкесии в одном из центров боспорской торевтики, находившимся под влиянием колхидского ювелирного искусства. Вклад авторов. Ю.А. Прокопенко выполнены работы по зарисовке броши, анализу литературы и электронных материалов по теме исследования и написанию текста. Совместно Ю.А. Прокопенко с С.Л. Кравцовой был проведен исследовательский морфологический анализ предмета для уточнения материалов и техник, использованных при его создании. С.Л. Кравцовой подготовлена «легенда» о фибуле-броши - информация о ее происхождении.

Ключевые слова: фибула-брошь, дисковидные привески, полые фигурки, скань, позднеэллинистический период, торевтика.

Цитирование. Прокопенко Ю. А., Кравцова С. Л. Фибула-брошь с привесками из кургана, исследованного в северных окрестностях города Черкесска // Вестник Волгоградского государственного университета. Серия 4, История. Регионоведение. Международные отношения. - 2019. - T. 24, № 5. - С. 19-33. - DOI: https:// doi.org/10.15688/jvolsu4.2019.5.2

Введение. В Ставропольском государственном историко-культурном и природноландшафтном музее-заповеднике им. Г.Н. Прозрителева и Г.К. Праве хранится редкое украшение - фибула-брошь с дисковидными привесками. Предмет был обнаружен 30 марта 1965 г. при снятии скрепером насыпи кургана, исследованного на территории совхоза Родина в северных окрестностях г. Черкесска (территория Карачаево-Черкесской автономной области; в настоящее время - Карачаево-Черкесская Республика), передан в фонды Ставропольского краевого музея научным сотрудником-археологом А.Л. Нечитайло ${ }^{1}$.
В 1991 г. данное украшение было представлено в составе выставки археологических предметов из памятников Северного Кавказа, экспонировавшейся в городе Токио. Здесь же опубликован иллюстрированный каталог, куда было включено и изображение броши, но без масштаба и с неполными сведениями об обстоятельствах ее находки [24, с. 91, № 87]. В результате вместо самой вещи эта фотография стала привлекаться исследователями в качестве предмета изучения [16, табл. Б/1,5; 23, с. 93, рис. 4, 4]. Отсюда в публикациях разночтения, касающиеся формы броши (круглая или овальная), также включены неверные размеры изделия, неправильные трак- 
товки зооморфных изображений («барашки» или «бычки»), отсутствие описания ряда деталей лицевой и оборотной сторон украшения. В связи с этим появилась необходимость в полноценной публикации украшения.

Методы. В качестве рабочего использован сравнительно-типологический метод. Он основан на классификации по материалу, способу обработки, форме, орнаменту, а также на выделении и исследовании типов брошей с привесками. Сравнительный анализ декора украшения из Ставропольского музея и подобных брошей с привесками, обнаруженных в западной части Северного Кавказа, позволяет охарактеризовать технологии производства полихромных украшений в регионе в III-І вв. до н. э.

Анализ. Фибула-брошь - сложное ювелирное украшение, выполненное из золота 916 пробы ${ }^{2}$. Изделие представляет собой пластину овальной формы, несколько деформированную и украшенную в полихромном стиле с размерами: $Д^{3}-55 \times 62$ мм (рис. 1 , фото 1$)$. Оно имеет валик-бортик, выполненный из напаянной на основу золотой проволоки, декорированной наклонными насечками (рис. 1). В центре пластины расположен глухой каст овальной формы. Конструкция состоит из вертикально расположенных, плотно подогнанных закругленных золотых лепестков (В - 4-5 мм), стянутых в нижней части золотой ажурной лентой в виде двух параллельных «косичек». Овал каста дополнительно обрамлен золотой рубчатой проволокой. Лепестки (Ш - 1,5-2 мм) имеют по краю выпуклые валики, окаймляющие вогнутую середину овальной формы. Каст плотно фиксирует черную с белыми разводами вставку овальной формы (размеры $21 \times 25$ мм), выполненную из раковины (мидия?) ${ }^{4}$.

Поле пластины разделено на четыре зоны симметрично расположенными (крестообразно), напаянными на пластину полыми объемными фигурками (выполнены из двух половинок), изображающими ланей с подогнутыми ногами, обращенными головками к краям изделия (Дл - 16-19; В - 13-15; Т - 3-4 мм). У одной из фигурок деформировано туловище, другая частично смята (разрушен шейный соединительный шов). Рельефно, в технике «чеканки» показаны параллельные шейные вали- ки (возможно, шейные складки самца в осенне-зимний период), передние и задние конечности. У двух фигурок в задней части фиксируется вертикальная вогнутость (деформированный шов спайки).

Головы животных вытянутой формы, заужены к носу. В одном случае у фигурки носовая часть покатая, напоминает морду сайгака. Остролистной формы уши выполнены из отдельных пластинок, припаянных к основе в лобной части фигурок. Вытянутые миндалевидные глаза рельефно оконтурены золотой рубчатой проволочкой. К зауженной части морды животных - в районе ноздрей - припаяны петли, к которым подвешены цепочки, выполненные из спиралевидно закрученной золотой проволоки (Дл - 7-8 мм) (рис. 1). Цепочки завершаются петлями, в которые вставлены миниатюрные полумесяцевидные бляшки (в одном случае бляшка утеряна) (Дл - 78 мм; Ш-2 мм). Лунницы декорированы тонкой рубчатой проволочкой по краю.

Форма глаз, вытянутые остролистные уши (Дл - 4-5 мм), особенности оформления деталей головы и крупа подчеркивают принадлежность изображенных животных к отряду парнокопытных - лани.

Каждый из четырех секторов пластины декорирован двумя рядами сканных изображений из рубчатой проволоки (по три) - в форме греческой буквы омега (внутренний ряд) и фигур из двух зеркально расположенных S-видных завитков (внешний ряд). Сердцевидные середины крайних сканных гнезд инкрустированы синей эмалью. Центральные фигуры декорированы каплевидными полупрозрачными вставками из голубоватой эмали или стекла (?) (в двух секторах в отдельных случаях эмаль либо сохранилась частично, либо утеряна).

По внутреннему краю бортика каждый сектор пластины дополнительно украшен напаянными на основу, плотно пригнанными к бортику шестью полыми полусферами, выполненными из золотого листа (всего 24 экземпляра).

Оборотная сторона пластины имеет в центральной части вогнутость овальной формы с рельефно выделенными краями - видимо, оборотный контур каста (Д - $24 \times 29$ мм). В центре прослеживается продольная полоса 


\section{АРХЕОЛОГИЯ ВОСТОЧНО-ЕВРОПЕЙСКИХ СТЕПЕЙ}

(Ш - 7-8 мм). В поле пластины - вокруг овальной вогнутости - наблюдаются точечные наколы - следы чеканки. Напротив продольно вытянутой части овала расположены: выступ овальной формы - остатки иглодержателя и напротив скобообразный приемник иглы (рис. 1).

К краю оборотной стороны пластины припаяны шесть петель из золотой проволоки (Д $-4 \times 5$ мм), в которые вставлены сложно сплетенные из четырех золотых проволочек «из петли в петлю» цепочки (Дл 52-59 мм). Их концы завершаются петлями, в которые вставлены дисковидные привески (Д - 9 мм), декорированные проволочным рубчатым бортиком.

В настоящее время известно о семи находках (включая выше отмеченную) позднеэллинистических брошей-застежек с подвесками на цепочках, выявленных на территории Кубани, Центрального Предкавказья и Крыма: круглая брошь с пятью подвесками - аул Ново-Вочепший (рис. 2, 3) [16, таб. 61, Б/1.10; 23 , с. 90 , рис. 4,2$]$; круглая брошь с четырьмя (?) подвесками - курган 1, объект 9 Курганинского кургана-кладбища (рис. 2, 1) [3, c. 128 , табл. 4в, $120 ; 16$, табл. 31 , А119, 14 , рис. $22 ; 23$, с. 90 , рис. 4,$3 ; 26$, fig. 17,7$]$; круглая брошь с шестью подвесками - погребение 177 Тенгинского могильника (рис. 2, 2) [2, с. 177 , рис. 3,$4 ; 16$, таб. 41 , А270, 4 ; 23, с. 90 , рис. 4,1$]$; круглая брошь с семью подвесками - Псенафа (окраина г. Майкоп) (рис. 3, 1-2) [23, с. 89, рис. 2-3]; круглая брошь с пятнадцатью подвесками (одна утеряна) на восьми цепочках из Прикубанья (?) (частная коллекция в Англии) (рис. 2, 4) [23, с. 92, рис. 5, 1; 25, p. 58-59, № 15]; брошь с петельками (цепочки и подвески утеряны) - Ногайчикский курган [16,А159.21, рис. 18; 23, с. 93-95].

По мнению В.Р. Эрлиха, наиболее близко по оформлению к броши из Ставропольского музея-заповедника подобное изделие с привесками из Псенафы. Автор датировал оба украшения III-II вв. до н. э. [23, с. 95].

Следует отметить, что скорее всего прототипом для брошей с крестообразно расположенными зооморфными фигурками являются более ранние античные украшения дисковидной формы с объемными фигурками, украшенными зернью (напоминающие колхидс- кие изделия). В частности, такой диск с размещенными крестообразно фигурками пчел (Д - 4 см; № 2006.1.218) экспонируется в Музее искусств Нэшера в Университете Дюка (г. Дарем, Северная Каролина - США). Сюда украшение поступило из коллекции Уолтера Кемпнера. На основании особенностей декорирования зернью сотрудники Музея диск датируют VII в. до н. э. По их мнению, такая технология была характерна для ювелирного искусства Восточного Средиземноморья в VIII-VII вв. до н. э., в частности, имеет сходство с группой украшений с острова Родос, начиная с 650-600 гг. до н. э. (рис. 2, 5) [28]. Однако украшение зернью, в том числе треугольниками из зерни, является отличительной особенностью и колхидских украшений.

Указанные броши из Карачаево-Черкесии и Псенафы объединяют: крестообразная схема расположения зооморфных фигурок, бортик из рубчатой проволоки, каст со вставкой, наличие цепочек с дисковидными привесками и бляшек-лунниц. Однако детальный анализ зооморфных изображений и особенностей декора внутреннего пространства пластины между фигурками позволяет нам подвергнуть сомнению утверждение В.Р. Эрлиха. Кроме общего принципа создания фигурок из двух половинок ничего общего между ланями на броши из совхоза Родина и «птичками» (?) украшения из Псенафы не прослеживается.

Полые металлические (золотые и др.) фигурки, изображающие сидящих птиц, появляются в Центральном Предкавказье и в прилегающих районах в памятниках III в. до н. э. (например, ст. Казбек [раскопки 1879 г.]) (рис. 4,4$)$. Однако такие изображения имеют черты, присущие именно птицам: голова, завершающаяся клювом, сложенные крылья и хвост. Интересно, что, видимо, под влиянием такого образа, воплощенного в золоте, в Центральном Предкавказье начинается производство полых птичек из бронзового листа. Их местная особенность - наличие вертикально поставленных ушей (возможно, рудимент ушастых литых «птичек» кобанской культуры) (гробница, исследованная Л.Н. Глушковым в г. Ставрополь на ул. Орджоникидзе в 1965 г.) (рис. 4, 5) [18, с. 495, рис. 90Е, 18].

Стилизация изображения из Псенафы более близка целой серии сложно идентифи- 
цируемых фигурок из комплексов II в. до н. э. І в. н. э., у которых показаны только голова и туловище без выделенных конечностей. Это могут быть барашки и лошади. Например, серьга в виде барана (?) - находка на Пашковском городище 6 (рис. 4, б); фибула-застежка в форме «барашка» из погребения 5 кургана 1 у г. Армавир, фибула-застежка «барашек» из впускного погребения «Большого» кургана у г. Армавир, серьги в виде протомы барана или лошади (?) из кургана 1 у ст. Раздольной (рис. 3,4 ), подвеска в виде лошади из аула Тайухабль (рис. 3,3 ) [8, табл. XIV, 72,$84 ; 22$, с. 134 , рис. 60 , № 171,$188 ; 23$, с. 94 , рис. 5,2$]$. В последних двух случаях фигурки имеют дисковидные привески, подвешенные на цепочках. Все перечисленные варианты изображений декорированы сканью (в том числе шейной части - грива?), что также сближает их с фигурками на броши из Псенафы. Подчеркнем, что других подобных стилизованных изображений «птичек» пока не обнаружено.

Следует предположить, что такой упрощенный вариант моделировки зооморфных образов связан с продолжением традиции создания подобных (полых) изображений - в виде протомы или фигурок без оформления конечностей, характерных для золото-кузнечного дела Колхиды V-IV вв. до н. э. В конце V - IV в. до н. э. они поступают в Центральное Предкавказье. В частности, такое изображение протомы «козлика» (?) с тремя горизонтально расположенными бусинами выявлено в кургане 8 могильника Орджоникидзевский (конец V-IV в. до н. э.) (рис. 4, 2) [5, c. 367 , рис. 13,2$]$. Две подвески в виде «сидящего барана» с бусиной обнаружены у аула Гойты в 1888 г. (рис. 4, 3) [18, с. 644, рис. 210, $13,14]$. Подвеска в виде двух протом лошадей, происходящих из погребения 22 могильника Гастон-Уота (первая половина IV в. до н.э.) (рис. 4,1 ), и две аналогичные подвески из коллекции С.Н. Платонова (г. Киев), возможно, поступившие из северокавказского памятника (рис. 4, 10-11) [17, с. рис. 27, 16; 20, c. 340 , рис. $10,1,2]$. В гробнице кургана Карагодеуашх (конец IV - начало III в. до н. э.) обнаружено золотое ожерелье, центральной деталью которого является голова быка с привешенной к шейной части амфоровидной привеской [13, табл. IV, 2] (рис. 4, 14). Реже встречаются подвески в виде протомы хищников. В частности, такое украшение было представлено в наборе зооморфных фигурок, выявленных в Курджипском кургане [20, рис. 5, 5] (рис. 4, 17).

Как уже было отмечено, у фигурок на броши из Карачаево-Черкесии проработаны конечности, это коренным образом отличает их от выше перечисленных. В целом в сравнении с другими изображениями эти фигурки более профессионально выполнены. При этом мастер, создававший это украшение для показа деталей зооморфных изображений, использовал другие приемы. Вместо сканного декора шейная часть показана рельефными валиками с помощью чеканки. Таким же образом смоделированы другие объемные части фигурок - круп, передние и задние конечности. Рубчатая проволочка использована только для окантовки глаз. Отличает брошь из совхоза Родина и сложная композиция размещения сканных фигур в четырех секторах пластины в два ряда (в случае с псенафским вариантом размещения - более простой декор из «жемчужника», оконтуренного рубчатой проволокой, размещенный только вдоль бортика). Также на броши из Карачаево-Черкесии вместо выбитых пуансоном «жемчужин» вдоль бортика размещены припаянные полые полусферы. Центральный каст украшения из Псенафы состоит из грубо выделанных лепестков, вдобавок неплотно пригнанных друг к другу. Видимо, поэтому вставка является подвижной. Наиболее близкой по форме и качеству оформления каста в виде плотного ряда закругленных лепестков, стянутых золотой лентой в нижней части, является великолепная овальная брошь со вставкой - инталией из агата, обнаруженная в кургане III-II в. до н. э. у станицы Брюховецкой [22, с. 49, рис. XXXV, кат. № 144] (рис. 4, 7).

Случаев использования сложного узора, подобного фигурам на броши из КарачаевоЧеркесии, при декорировании других украшений нам не известно. Нужно отметить отдаленно напоминающий вариант оформления поля пластины у овальной броши из захоронения у хутора Рассвет (II-I вв. до н. э.). В данном случае более простой декор состоит из двух рядов S-видных завитков, направленных 


\section{АРХЕОЛОГИЯ ВОСТОЧНО-ЕВРОПЕЙСКИХ СТЕПЕЙ}

в одну сторону (вокруг каста), выполненных из рубчатой проволоки. Характерно, что в этом случае лента, стягивающая лепестки каста подобно украшению из Ставропольского музея, представляет собой две линии скани в виде «косички» (рис. 4, 13) [27, с. 72, 80, fig. 2].

Важнейшим отличительным (морфологическим и хронологическим) признаком украшения из Ставропольского музея также является использование в качестве декора темно синей эмали. Это позволяет отнести указанную брошь к кругу боспорских украшений с инкрустацией. Следует отметить, что эмаль в отдельных случаях использовалась и для декорирования золотых предметов в ювелирных мастерских Колхиды (ожерелье из полых черепах, глаза которых инкрустированы стекловидной пастой - Вани; украшение с альмандинами в сочетании с зеленой эмалью - Вани (IV в. до н. э.) [15, с. 194, рис. 11; 10]. Однако особенности формы вставок (сердцевидные и каплевидные) подчеркивают именно боспорское происхождение броши из Карачаево-Черкесии. Инкрустация подобным образом зафиксирована у значительной части золотых боспорских украшений второй половиной $\mathrm{V}$ - pyбежом IV-III вв. до н. э.: серьги в виде сфинксов выявлены в кургане «Три брата» в окрестностях г. Керчь (IV в. до н. э.) (лепестки розетки на петле изделия и закругленные гнезда-лепестки в постаменте инкрустированы синей и зеленой эмалью) [12, с. 183-184, рис. 5]; золотые подвески - медальоны с желудевидными привесками (украшены розеттами и листьями плюща, покрытыми синей эмалью), гривна с фигурками скифов-всадников (концы гривны перед всадниками декорированы вставками с синей и зеленой эмалью) и височные подвески с изображением головы Афины (диск-медальон с прикрепленной к нему ажурной подвеской в виде сетки из цепочек и розеток, инкрустированных цветной эмалью) обнаружены в кургане Куль-Оба (IV в. до н. э.) [4, с. 38-103; 9]; калаф (меандр и розетки инкрустированы синей эмалью) и височная подвеска с изображением Нереиды на гиппокампе (подвески декорированы синей эмалью) найдены в кургане Большая Близница (конец IV в. до н. э.) [1, с. 68, табл. 284, 285, 296, 300; 11; 21, кат. № 202, 203]; поясные застежки с инкрустацией синей эма- лью входили в погребальный инвентарь Курджипского кургана (конец IV - начало III в. до н. э.) [13, с. 85 , рис. 19].

Из перечисленных украшений в трех случаях вставки кроме каплевидной имели и сердцевидную форму, аналогичную декору броши из Карачаево-Черкесии (височные подвески из кургана Куль-Оба, а также височные подвески с изображением Нереиды на гиппокампе и многослойные розетки с сердцевидными лепестками из кургана Большая Близница).

Таким образом, украшение из Ставропольского музея более раннее - не позже начала III в. до н. э. - чем брошь из Псенафы конец III - II в. до н. э.

Как уже было отмечено, у найденных украшений III-I вв. до н. э., выполненных в виде зооморфных изображений (сидящих, но без выделения конечностей), есть общий прототип - ранние колхидские украшения $\mathrm{V}-$ IV вв. до н.э. Более изящные фигурки животных на пластине броши из совхоза Родина также показаны в положении сидя, но с детализированной проработкой передних и задних ног. Прототипом этого варианта являются объемные колхидские изображения другого варианта - сидящих животных с оформлением нижних конечностей, видимо, под влиянием переднеазиатского звериного стиля или античного искусства. Например, в близкой технике выполнены золотые полые фигурки пегасов (с привесками к носам) и фигурка, изображающая лежачего хищника (пантеру?), из Курджипского кургана второй половины IV в. до н. э. (рис. 4, 8, 16), золотые объемные фигурки львов (с согнутыми в сидящем положении лапами), обнаруженные в погребении 44 могильника Уляп I (рис. 4, 9), золотая полая фигурка кабана (из двух половинок) с подогнутыми конечностями из погребения 24 III-II вв. до н. э. кургана 1 Комаровского могильника (рис. 4,15 ) $[6$, рис. $1,11,12 ; 7$, с. 84,$17 ; 14$, с. 76,109 , рис. 34,$12 ; 19$, с. 102 , рис. 106 , a, b].

Результаты. Следует предположить, что зооморфные фигурки на броши из Карачаево-Черкесии являются свидетельством влияния колхидского «златокузнечества» на боспорское ювелирное искусство. Кроме того, стоит отметить, что для второй половины IV начала III в. до н. э. характерны синкретичные украшения, включающие элементы двух 
ювелирных школ. В частности, к подобным следует отнести калаф с подвесками в виде буковых орешков из гробницы 1 Трехбратнего кургана [20, с. 512] и, возможно, ожерелье с пластинками-плакетками и амфоровидными привесками с центральной деталью в виде головы быка из кургана Карагодеуашх [13, табл. IV, 2].

Таким образом, следует заключить, что в производстве полых зооморфных изображений III-I вв. до н. э. наблюдаются две линии развития: 1) упрощенная моделировка фигурок по образцу колхидских изделий V-IV вв. до н. э. (Псенафа и др.); 2) продолжение традиции производства украшений с эмалью (брошь из кургана на земле совхоза Родина). Если в первом случае простота и небрежность исполнения свидетельствуют о налаженном местном производстве подражаний колхидским изображениям, то во втором изящность изображений и изысканность исполнения подчеркивают создание броши из Карачаево-Черкесии в одном из центров боспорской торевтики, возможно находившимся под влиянием колхидского ювелирного искусства. В связи с этим следует отметить, что у фигурок броши из Ставропольского музея-заповедника присутствуют признаки, которые М.Ю. Трейстер считает «маркерами» колхидской ювелирной школы, - это подвески в носу животных и уши, свернутые из отдельных пластинок, припаянные к основе [20, с. 510].

\section{ПРИМЕЧАНИЯ}

${ }^{1}$ Брошь хранится в фондах Ставропольского государственного историко-культурного и природно-ландшафтного музея-заповедника им. Г.Н. Прозрителева и Г.К. Праве. Выражаем искреннюю признательность коллективу отделов археологии и природы СГМЗ и лично директору Музея Н.А. Охонько за оказанное содействие в процессе изучения украшения и предоставленную возможность публикации броши; Книга поступлений Ставропольского государственного краевого музея - акт № 44 от 17 февраля 1969 г.; Инвентарная книга № 19 археологическая коллекция «Археологические памятники эпохи раннего железа» - шифр АЖ Т. № 1. Хранится - спец. хранилище СГМЗ № ОФ 15441/1, АЖ 101, СЧ № 36 .

${ }^{2}$ Предмет прошел апробирование в Донской Государственной инспекции апробирного надзора в г. Ростов-на-Дону.

${ }^{3}$ Д - диаметр; Дл - длина; В - высота; Ш ширина; Т - толщина.

${ }^{4}$ Приносим искреннюю признательность геологу, научному сотруднику отдела природы СГМЗ Н.Р. Кочневой за определение материала вставок в касте и в сканных фигурах. 


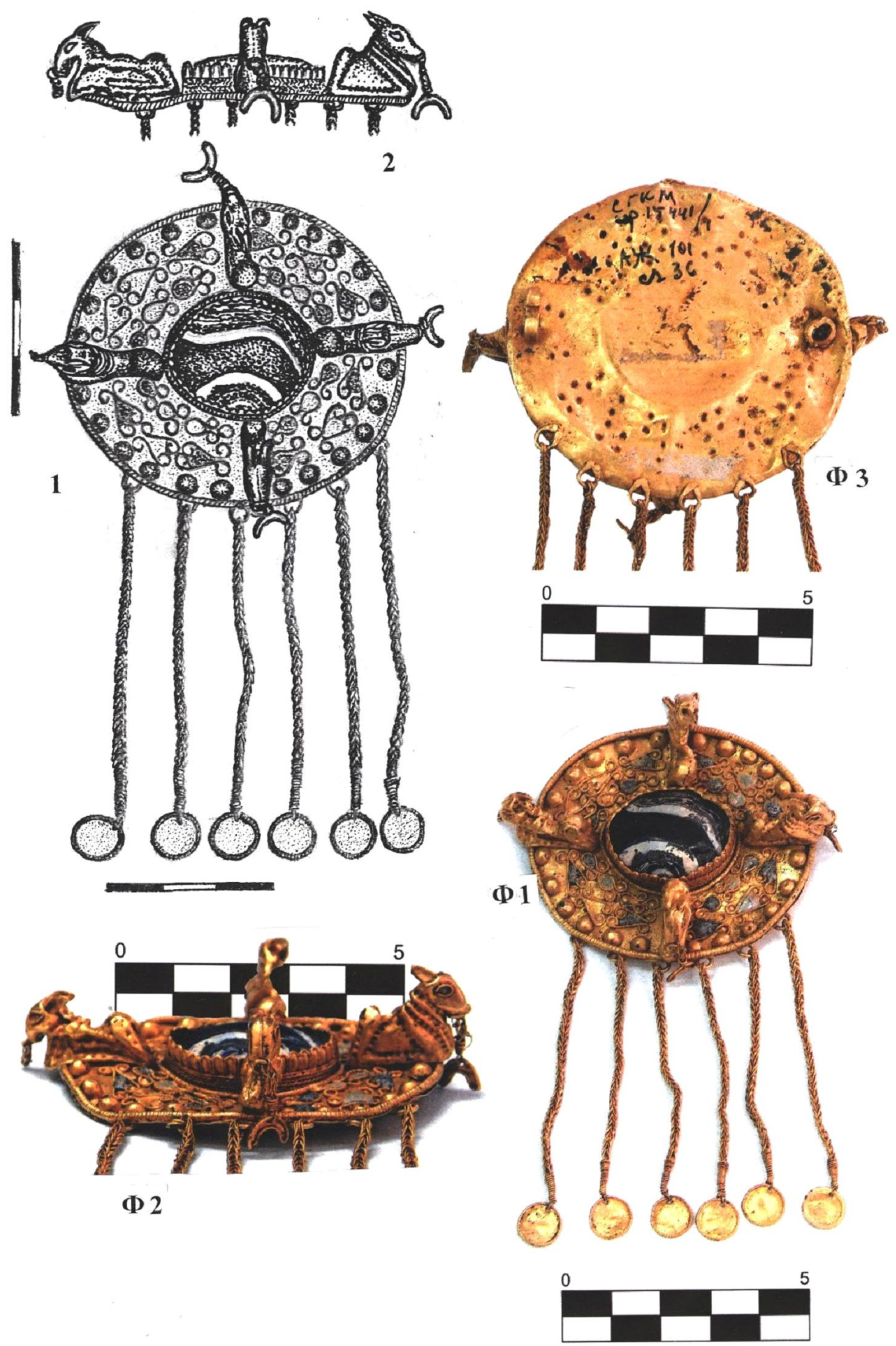

Рис. 1. Фибула-брошь из кургана, раскопанного на земле совхоза Родина (Карачаево-Черкесская Республика):

1 - лицевая сторона; 2 - профильное изображение; $\Phi 1$ - лицевая сторона; $\Phi 2$ - профильное изображение; $Ф 3$ - оборотная сторона

Fig. 1. Fibula-brooch from the mound excavated on the ground of Rodina state farm (The Republic of Karachaevo-Cherkessia):

1 - front side; 2 - profile image; $F 1$ - front side; $F 2$ - profile image; $F 3$ - reverse side 

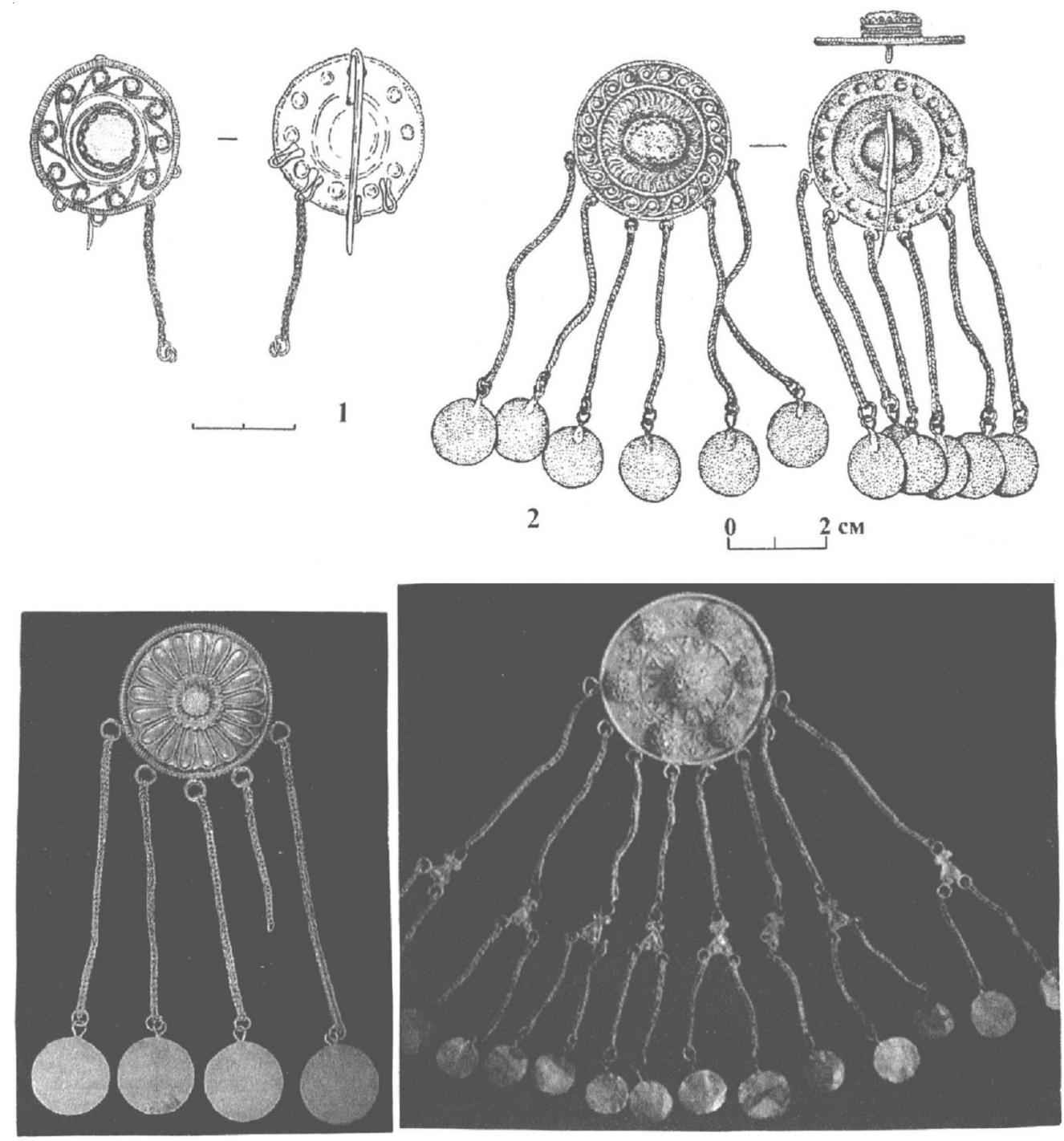

3

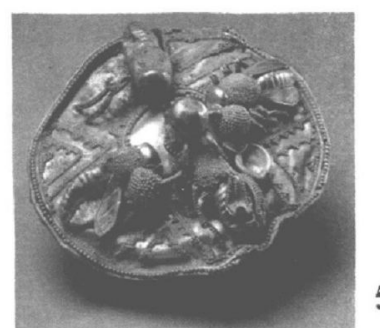

Рис. 2. Фибулы-броши с привесками из памятников Северного Кавказа и диск с пчелами (все - золото): 1 - фибула-брошь из кургана 1, объекта 9 Курганинского кургана-кладбища (по Raev, Simonenko, Treister, 1991); 2 - фибула-брошь из погребения 177 Тенгинского грунтового могильника (по Беглова, 2005); 3 - фибула-брошь из аула Ново-Вочепший (по Мордвинцева, Трейстер, 2007); 4 - фибула-брошь из частной коллекции в Англии (по Эрлих, 2013);

5 - диск, украшенный фигурками пчел из Музея искусств Нэшера в Университете Дюка

Fig. 2. Fibula-brooches with pendants from the monuments of the North Caucasus and a disc with bees (everything - gold):

1 - fibula-brooch from barrow 1, object 9 of Kurganinskiy mound-cemetery (Raev, Simonenko, Treyster, 1991); 2 - fibula-brooch from burial 177 of Tenghinka subsoil burial ground (Beglova, 2005); 3 - fibula-brooch from Novo-Vochepshiy aul (Mordvintseva, Treyster, 2007); 4 - fibula-brooch from a private collection in England (Erlikh, 2013);

5 - disc decorated with figures of bees from the Nasher Museum of Art at Duke University 


\section{АРХЕОЛОГИЯ ВОСТОЧНО-ЕВРОПЕЙСКИХ СТЕПЕЙ}
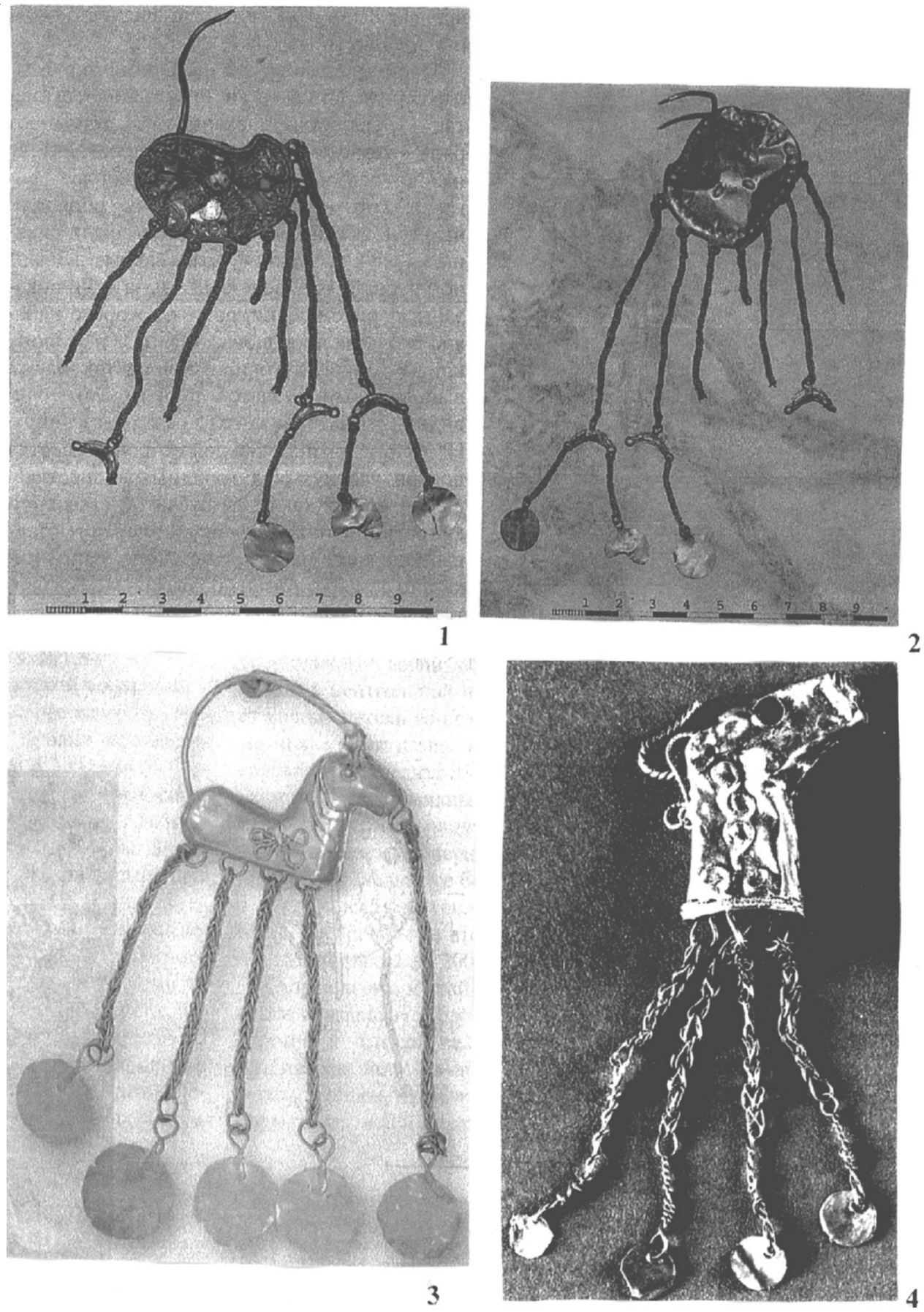

Рис. 3. Фибула-брошь и привески с цепочками (все - золото):

1-2 - фибула-брошь из кургана 1 Псенафа (окраина г. Майкопа) (по Эрлих, 2013);

3 - подвеска из Тауйхабля (по Эрлих, 2013); 4 - серьга в форме протомы барана или лошади (?) из кургана 1 у станицы Раздольной (по Шедевры ..., 1987)

Fig. 3. Fibula-brooch and pendants with chains (everything - gold):

1-2 - fibula-brooch from barrow 1 Psenafa (outskirts of Maikop) (Erlikh, 2013);

3 - pendant from Tauykhabl (Erlikh, 2013); 4 - earring in the shape of a sheep or horse protoma (?) from mound 1 near Razdolnaya stanitsa (Shedevry ... , 1987) 

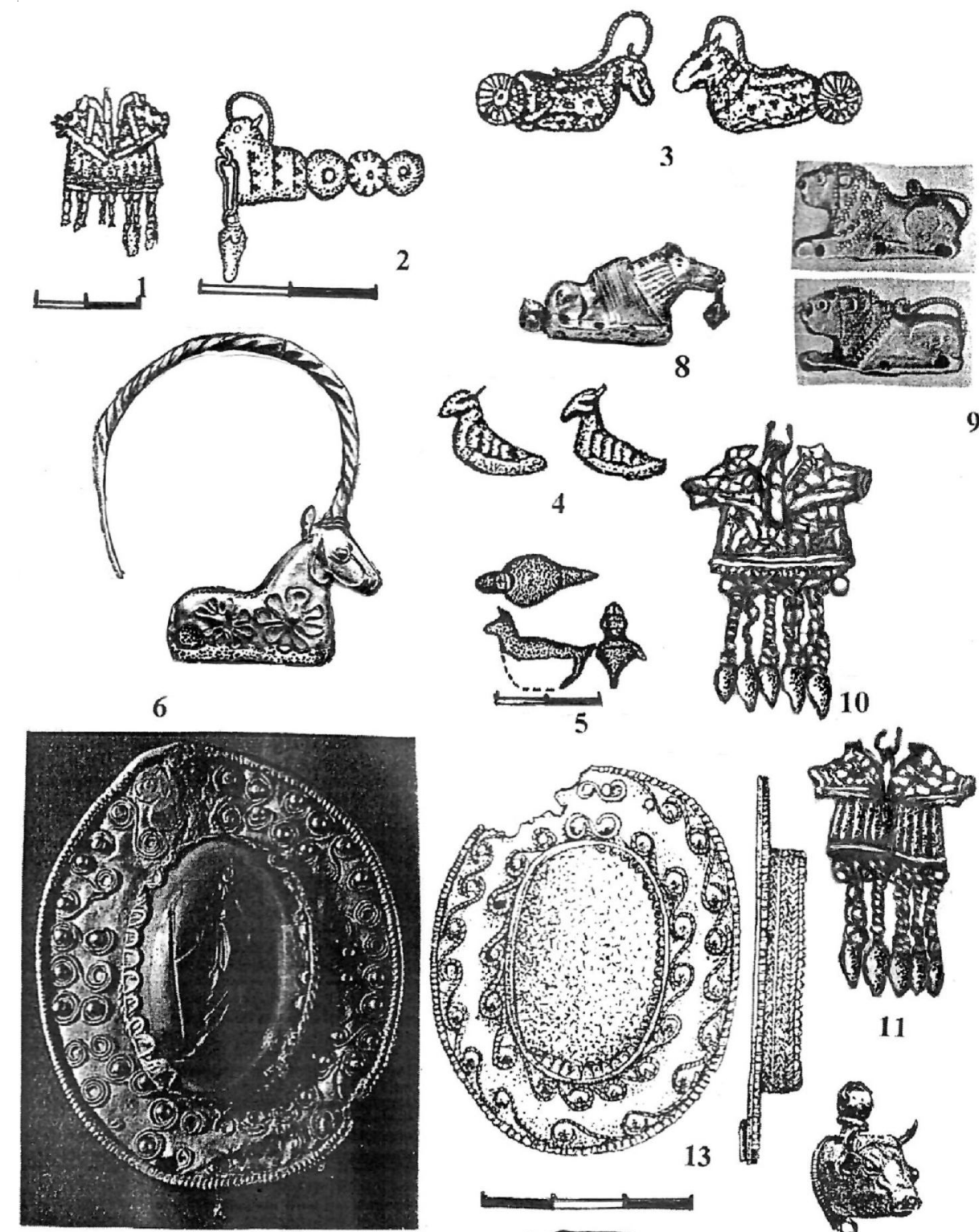

8
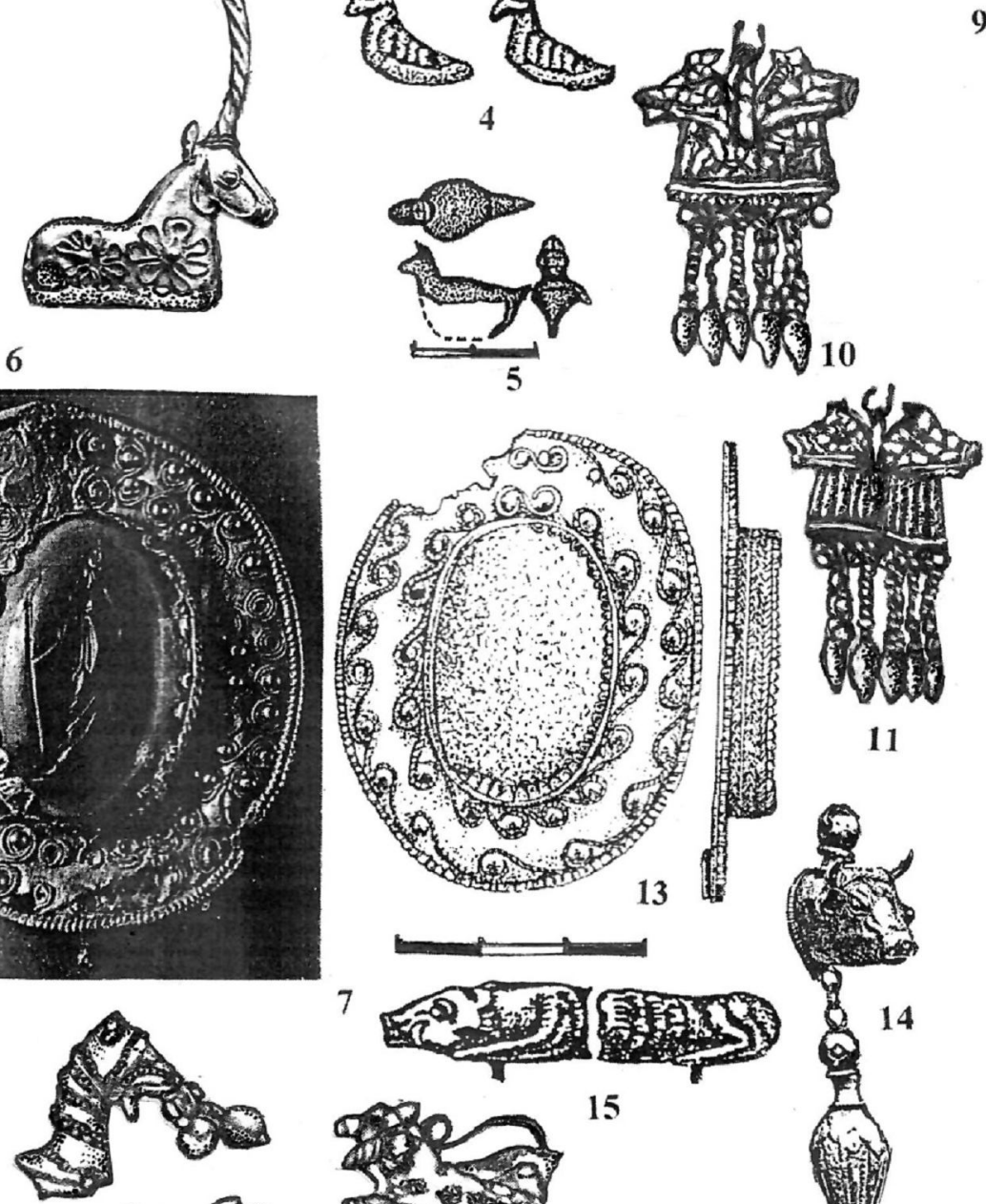

7

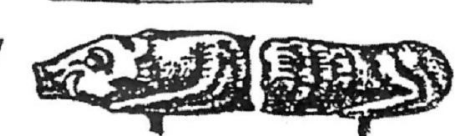

13
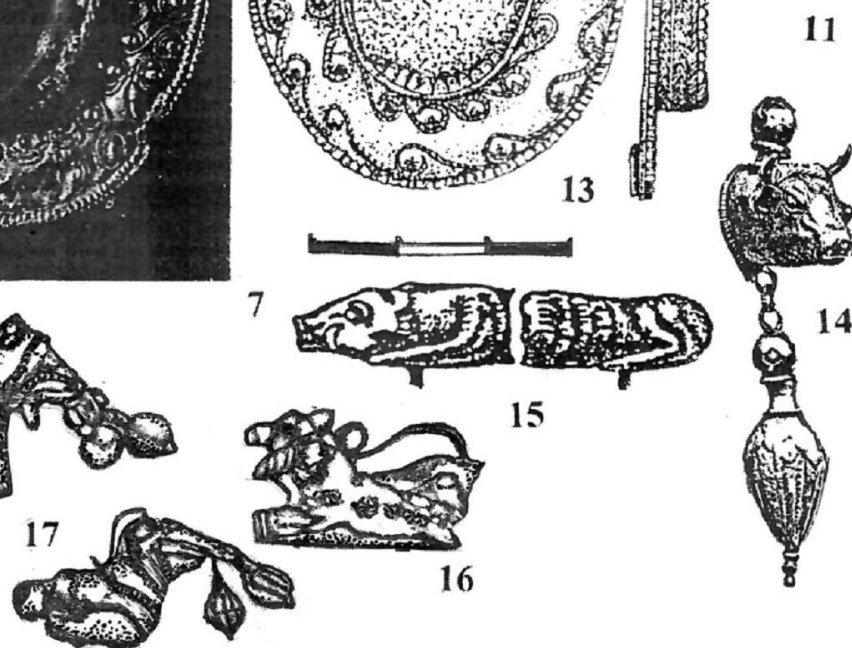

15

16

12

Рис. 4. Украшения и предметы звериного стиля конца V в. до н. э. - I в. н. э. из памятников Северного Кавказа (5 - бронза, остальные-золото):

1 - подвеска из погребения 22 могильника Гастон-Уота (по Мошинский, 2006);

2 - подвеска из кургана 8 могильника Орджоникидзевский (по Бурков, Маслов, 2005);

3 - подвески из аула Гойты (раскопки 1888 г.) (по Прокопенко, 2014);

4 - подвески из станицы Казбек (раскопки 1879 г.) (по Прокопенко, 2014);

5 - фигурка птицы из гробницы, исследованной Л.Н. Глушковым в г. Ставрополь на ул. Орджоникидзе в 1965 г. (по Прокопенко, 2014); 6 - серьга - находка на Пашковском городище 6 (по Шедевры ... , 1987);

7 - брошь из окрестностей станицы Брюховецкой (по Шедевры ..., 1987); 8 - привеска из Курджипского кургана 


\section{АРХЕОЛОГИЯ ВОСТОЧНО-ЕВРОПЕЙСКИХ СТЕПЕЙ}

(по Галанина, 1980); 9 - привески из погребения 44 могильника Уляп I (по Лесков и др., 2005); 10-11 - подвески из коллекции С.Н. Платонова (г. Киев) (по Трейстер, 2008);

12 - античное собрание. Государственные музеи Берлина - Прусское культурное наследство инв. 30629 (по Трейстер, 2008); 13 - брошь из захоронения у хутора Рассвет (по Raev 1997);

14 - центральная часть ожерелья из кургана Карагодеуашх (по Лаппо-Данилевский, Мальберг, 1894); 15 - фигурка кабана из погребения 24 кургана 1 Комаровского могильника (по Сокровища Алании, 2011); 16-17 - привески из Курджипского кургана (по Трейстер, 2008, прорисовка Ю. А. Прокопенко)

Fig. 4. Jewelery and objects of the animal style of the late $5^{\text {th }} \mathrm{c} . \mathrm{BC}-1^{\text {st }} \mathrm{c}$. AD from the monuments of the North Caucasus ( 5 - bronze, the others - gold):

1 - pendant from burial 22 of Gaston Wat burial ground (Moshinskiy, 2006); 2 - pendant from mound 8 of Ordzhonikidze burial ground (Burkov, Maslov, 2005);

3 - pendants from Goyta aul (excavations of 1888) (Prokopenko, 2014);

4 - pendants from Kazbek stanitsa (excavations 1879); (Prokopenko, 2014);

5 - bird figurine from the tomb investigated by L.N. Glushkov in Stavropol on Ordzhonikidze Street in 1965

(Prokopenko, 2014); 6 - earring - a finding on Pashkovskiy hillfort 6 (Shedevry ... , 1987);

7 - brooch from the surrounding areas of Bryukhovetskaya stanitsa (Shedevry ..., 1987); 8 - pendant from Kurdzhipskiy mound

(Galanina, 1980); 9 - pendants from burial 44 of Ulyap I burial ground (Leskov et al., 2005);

10-11 - pendants from the collection of S.N. Platonov (Kiev) (Treyster, 2008);

12 - antique collection. State Museums of Berlin-Prussian cultural heritage. Inventory number 30629 (Treyster, 2008); 13 - brooch from the burial near Rassvet khutor (Raev, 1997);

14 - central part of the necklace from Karagodeuashkh mound (Lappo-Danilevskiy, Malberg, 1894);

15 - wild boar figurine from burial mound 24 of barrow 1 of Komarovskiy burial ground (Sokrovishcha Alanii, 2011); 16-17 - pendants from Kurdzhipskiy mound (Treyster 2008, drawing by Yu.A. Prokopenko) 


\section{СПИСОК ЛИТЕРАТУРЫ}

1. Артамонов, М. И. Сокровища скифских курганов в собрании Государственного Эрмитажа / М. И. Артамонов. - Прага-Ленинград : Артия, Советский художник, 1966. - 120 с.

2. Беглова, Е. А. Богатое женское погребение из Тенгинского грунтового могильника / Е. А. Беглова // Материальная культура Востока. Вып. 4. - М. : Изд-во Гос. музея Востока, 2005. - С. 166-182.

3. Берлизов, Н. Е. Сарматские памятники Восточного Закубанья. Хронология и хронография / Н. Е. Берлизов, И. В. Каминская, В. Н. Каминский // Историко-археологический альманах. - Армавир-Москва : ИА РАН, 1995. - С. 120-132.

4. Брашинский, И. Б. В поисках скифских сокровищ / И. Б. Брашинский. - Ленинград : Наука, 1979. $-144 \mathrm{c}$.

5. Бурков, С.Б., Маслов, В.Е. Исследования могильника «Орджоникидзевский» в Чечне / С.Б. Бурков, В.Е. Маслов // Древности Евразии от ранней бронзы до раннего средневековья памяти В.С. Ольховского : сб. ст. - М. : ИА РАН, 2005. - С. 356-382.

6. Галанина, Л. К. Впускное погребение І в. н. э. Курджипского кургана / Л. К. Галанина // Советская археология. - 1973. - № 2. - С. 45-59.

7. Галанина, Л. К. Курджипский курган/Л. К. Галанина. - Ленинград : Искусство, 1980. - 127 с.

8. Гущина, И. И. Погребения зубовско-воздвиженского типа из раскопок Н.И. Веселовского в Прикубанье (І в. до н. э. - II в. н. э.) / И. И. Гущина, И. П. Засецкая // Труды ГИМ. Вып. 70. Археологические исследования на юге Восточной Европы. М. : ГИМ, 1989. - С. 71-141.

9. Древнее золото Керчи. - Электрон. текстовые дан. - Режим доступа: http.://artarion.livejournal.com (дата обращения: 04.03.2018). - Загл. с экрана.

10. Золото Медеи / Грузинская эмаль. - Электрон. текстовые дан. - Режим доступа: http.:// georgianenamel.mirtesen.ru (дата обращения: 04.03.2018). - Загл. с экрана.

11. Золотые украшения из кургана Большая Близница. - Электрон. текстовые дан. - Режим доступа: http.://ornament-I-stil.livejournal.com (дата обращения: 04.03.2018). - Загл. с экрана.

12. Кирилин, Д. С. Трехбратние курганы в районе Тобечикского озера / Д. С. Кирилин // Античная история и культура Средиземноморья и Причерноморья : сб. ст. / отв. ред. В. Ф. Гайдукевич. - Ленинград : Наука, 1968. - 349 с.

13. Лаппо-Данилевский, А. Древности Южной России. Курган Карагодеуашх / А. Лаппо-Данилевский, В. Мальберг // Материалы по археологии России. -1894 . - № 13. - С. 90-126.

14. Лордкипанидзе, О. Д. Городище Вани в общеколхидском контексте / О. Д. Лордкипанидзе
// Греция. Эллинизм. Причерноморье. - М. : Наука, 1992. - C. 184-208.

15. Меоты Закубанья в середине VI - начале III века до н. э. Некрополи у аула Уляп. Погребальные комплексы / А. М. Лесков [и др.]. - М. : Наука, 2005. $-182 \mathrm{c}$.

16. Мордвинцева, В. И. Произведение торевтики и ювелирного искусства в Северном Причерноморье / В. И. Мордвинцева, М. Ю. Трейстер. Симферополь-Бонн : Тарпан, 2007. - 308 с.

17. Мошинский, А. П. Древности горной Дигории VII-IV вв. до н. э. / А. П. Мошинский. - М. : ГИМ, 2006. $-256 \mathrm{c}$.

18. Прокопенко, Ю. А. Скифы, сарматы и племена кобанской культуры в Центральном Предкавказье во второй половине I тыс. до н. э. : в 2 ч. Ч. 2 / Ю. А. Прокопенко. - Ставрополь : Изд-во СКФУ, 2014. - 725 c.

19. Сокровища Алании / науч. ред. М. М. Блиев. - М. : Эксмо, 2011. - 239 с.

20. Трейстер, М. Ю. Колхидские ювелирные изделия V-IV вв. до н. э. за пределами Колхиды / М. Ю. Трейстер // Древности Боспора. Т. 12, ч. II. - М. : ИА РАН, 2008. - С. 506-540.

21. Уильямс, Д. Греческое золото, ювелирное искусство классической эпохи V-IV вв. до н. э. Каталог выставки / Д. Уильямс, Д. Огден. - СПб : Славия, 1995. -272 с.

22. Шедевры древнего искусства Кубани. Каталог выставки. - М. : Внешторгиздат, 1987. - 188 с.

23. Эрлих, В. Р. Фибула-брошь из святилища археологического комплекса Псенафа (предварительная публикация) / В. Р. Эрлих // Древности Западного Кавказа. Вып. 1. - Краснодар : Гранат, 2013. -С. 89-97.

24. Catalog Tokyo. The Treasures of Nomadic tribes in South Russia. - Tokyo : The Ancient Orient Museum, 1991.- $181 \mathrm{p}$.

25. Masterpieces of Ancient European and North American collection $6^{\text {th }}$ Cent. BC $-2^{\text {nd }}$ Cent. A.D. № 15. - London : [s. n.], 2008. -87 p.

26. Raev, B. Etrusco-Italik and Celtic Helmets in Eastern Europe / B. Raev, A. Simonenko, M. Treister // Jahrbuch RGZM. - 1991. - Bd. 38/2. - S. 465-496.

27. Raev, B. New Finds of the Alanian Graves With Import Goods in the Krasnodar Region / B. Raev // Adalya. - 1997. - № II. - P. 71-85.

28. Works of «Antiquitcs». - Electronic text data. - Mode of access: http.://lmuseum.nasher.duke. edu (date of access: 06.03.2018). - Title from screen.

\section{REFERENCES}

1. Artamonov, M.I. Sokrovishcha skifskikh kurganov v sobranii Gosudarstvennogo Ermitazha [Treasures of Scythian Burial Mounds in the 


\section{АРХЕОЛОГИЯ ВОСТОЧНО-ЕВРОПЕЙСКИХ СТЕПЕЙ}

Hermitage Collection]. Praga-Leningrad, Artiya Publ., Sovetskiykhudozhnik Publ., 1966. 120 p.

2. Beglova E.A. Bogatoe zhenskoe pogrebenie iz Tenginskogo gruntovogo mogilnika [Rich Female Burial Ground from the Burial of Tenghinka]. Materialnaya kultura Vostoka. Vyp. 4 [Material Culture of the East. Issue 4]. Moscow, Izd-vo Gosudarstvennogo muzeya Vostoka, 2005, pp. 166-182.

3. Berlizov N.E., Kaminskaya I.V., Kaminskiy V.N. Sarmatskie pamyatniki Vostochnogo Zakubanya. Khronologiya i khronografiya [Sarmatian Monuments of Eastern Zakubanye. Chronology and Chronography]. Istoriko-arkheologicheskiy almanakh [Historical and Archaeological Almanac]. Armavir-Moscow, IA RAN, 1995, pp. 120-132.

4. Brachinskiy I.B. V poiskakh skifskikh sokrovishch [In Search of Scythian Treasures]. Leningrad, Nauka Publ., 1979. 144 p.

5. Burkov S.B., Maslov V.E. Issledovaniya mogilnika "Ordzhonikidzevskiy” v Chechne [Research repository "Ordzhonikidze" in Chechnya]. Drevnosti Evrazii ot ranney bronzy do rannego srednevekovya pamyati V.S. Olkhovskogo : sb. st. [Antiquities of Eurasia from the Early Bronze Age to the Early Middle Ages in Memory of V.S. Olkhovskiy. Collected Articles]. Moscow, IA RAN, 2005, pp. 356-382.

6. Galanina L.K. Vpusknoe pogrebenie I v. n. e. Kurdzhipskogo kurgana [Inlet Burial of the $1^{\text {st }} \mathrm{c}$. AD in Kurdzhipskiy Mound]. Sovetskaya arkheologiya, 1973, no. 2, pp. 45-59.

7. Galanina L.K. Kurdzhipskiy kurgan [Kurdzhipsky Mound]. Leningrad, Iskusstvo Publ., 1980. 127 p.

8. Gushchina I.I., Zasetskaya I.P. Pogrebeniya zubovsko-vozdvizhenskogo tipa iz raskopok N.I. Veselovskogo v Prikubanye (I v. do n. e. - II v. n. e.) [Burial of Zubovskaya-Vozdvizhenskoe Type of Excavation of N.I. Veselovskiy in Kuban $\left(1^{\text {st }} \mathrm{c}\right.$. BC $2^{\text {nd }}$ c. AD)]. Trudy GIM. Vyp. 70. Arkheologicheskie issledovaniya na yuge Vostochnoy Evropy [Works of the State Historical Museum. Issue 70. Archaeological Research in the South Eastern Europe]. Moscow, GIM, 1989, pp. 71-141.

9. Drevnee zoloto Kerchi [Ancient Gold of Kerch] URL: http.://artarion.livejournal.com (accessed 4 March 2018).

10. Zoloto Medei / Gruziskaya emal [Gold of Medea/Georgian Enamel] URL: http.://georgianenamel. mirtesen.ru (accessed 4 March 2018).

11. Zolotye ukrasheniya iz kurgana Bolshaya Bliznitsa [Gold Jewelry from Bolshaya Bliznitsa Mound] URL: http.://ornament-I-stil.livejournal.com (accessed 4 March 2018).

12. Kirilin D.S. Trekhbratnye kurgany v rayone Tobechikskogo ozera [Trehbratnie Mounds in the Area of Lake Tobechikskoe]. Gaydukevich V.F., ed.
Antichnaya istoriya i kultura Sredizemnomorya $i$ Prichernomorya : sb. st. [Ancient History and Culture of the Mediterranean and Black Sea. Collected Articles]. Leningrad, Nauka Publ., 1968. 349 p.

13. Lappo-Danilevskiy A., Malberg V. Drevnosti Yuzhnoy Rossii. Kurgan Karagodeuashkh [Antiquities of Southern Russia. Karagodeuashkh Mound] Materialy po arkheologii Rossii, 1894, no. 13 , pp. $90-126$.

14. Lordkipanidze O.D. Gorodishche Vani v obshchekolkhidskom kontekste [Vani Hillfort in the Context of the Whole Colchis]. Gretsiya. Ellinizm. Prichernomorye [Greece. Hellenism. Black Sea Coast]. Moscow, Nauka Publ., 1992, pp. 184-208.

15. Leskov A.M., Beglova E.A., Ksenofontova I.V., Erlikh V.R. Meoty Zakubanya v seredine VI-nachale III veka do n. e. Nekropoli u aula Ulyap. Pogrebalnye kompleksy [Meotians of Zakubanye in the Mid $6^{\text {th }}-$ Early $3^{\text {rd }}$ Century BC. Necropolis near Ulyap Aul. Funerary Complexes]. Moscow, Nauka Publ., 2005. $182 \mathrm{p}$.

16. Mordvintseva V.I., Treyster M.Yu. Proizvedenie torevtiki i yuvelirnogo iskusstva $v$ Severnom Prichernomorye [Artwork of Toreutics and Jewelry in the Northern Black Sea Coast]. SimferopolBonn, Tarpan Publ., 2007. 308 p.

17. Moshinskiy A.P. Drevnosti gornoy Digorii $V I I-I V v v$. do n.e. [Antiquities of Mountain Digoria of the $7^{\text {th }}-4^{\text {th }}$ Century BC]. Moscow, GIM, 2006. $256 \mathrm{p}$.

18. Prokopenko Yu.A. Skify, sarmaty i plemena kobanskoy kultury $v$ Tsentralnom Predkavkazye vo vtoroy polovine I tys. do n. e. : v 2 ch. Ch. 2 [Scythians, Sarmatians and Tribes of Kobane Culture in the Central Caucasus in the Second Half of the $1^{\text {st }}$ Millennium BC. In 2 Parts. Part 2]. Stavropol, Izd-vo SKFU, 2014. 725 p.

19. Bliev M.M., ed. Sokrovishcha Alanii [Alanya Treasures]. Moscow, Eksmo Publ., 2011.239 p.

20. Treyster M.Yu. Kolkhidskie yuvelirnye izdeliya V-IV vv. do n. e. za predelami Kolkhidy [Colchis Jewelry of the $5^{\text {th }}-4^{\text {th }} \mathrm{c}$. BC Outside of Colchis]. Drevnosti Bospora. T. 12, ch. II [Antiquities of the Bosporus. Vol. 12, Part 2]. Moscow, IA RAN, 2008, pp. 506-540.

21. Uilyams D., Ogden D. Grecheskoe zoloto, yuvelirnoe iskusstvo klassicheskoy epokhi $V-I V v v$. do n. e. Katalog vystavki [Greek Gold, Jewelry Art of the Classical Era of the $5^{\text {th }}-4^{\text {th }}$ c. BC. Exhibition Catalog]. Saint Petersburg, Slaviya Publ., 1995. 272 p.

22. Shedevry drevnego iskusstva Kubani. Katalog vystavki [Masterpieces of Ancient Kuban Art. Exhibition Catalog]. Moscow, Vneshtorgizdat, 1987. 188 p.

23. Erlikh V.R. Fibula-brosh iz svyatilishcha arkheologicheskogo kompleksa Psenafa (predvaritelnaya publikatsiya) [Fibula-Brooch of the Sanctuary Archaeological Complex of Psenafa (Pre- 
Publication)]. Drevnosti Zapadnogo Kavkaza. Vyp. 1 [Antiquities of Western Caucasus. Issue 1]. Krasnodar, Granat Publ., 2013, pp. 89-97.

24. Catalog Tokyo. The Treasures of Nomadic Tribes in South Russia. Tokyo, The Ancient Orient Museum, 1991. $181 \mathrm{p}$.

25. Masterpieces of Ancient European and North American Collection $6^{\text {th }}$ Cent. BC-2 $2^{\text {nd }}$ Cent. A.D. no. 15. London [without publishing], 2008.87 p.
26. Raev B., Simonenko A., Treyster M. EtruscoItalik and Celtic Helmets in Eastern Europe. Jahrbuch des Römisch-Germanischen Zentralmuseums, 1991, Bd. 38/2, S. 465-496.

27. Raev B. New Finds of the Alanian Graves With Import Goods in the Krasnodar Region. Adalya, 1997, no. 2, pp. 71-85.

28. Works of “Antiquitcs”. URL: http.://lmuseum. nasher.duke.edu (accessed 6 March 2018).

\section{Information about the Authors}

Yury A. Prokopenko, Doctor of Sciences (History), Associate Professor, Professor, Department of Social Philosophy and Ethnology, North-Caucasus Federal University Humanities Institute, Pushkina St., 1, 355009 Stavropol, Russian Federation, z proko 15@mail.ru, https://orcid.org/0000-0001-7060-5054

Svetlana L. Kravtsova, Head of the Department of Archeology, The G.N. Prozritelev and G.K. Prave Stavropol State History, Culture and Natural Landscape Reserve Museum, Dzerzhinskogo St., 135, 355035 Stavropol, Russian Federation, vetochkakaleo@mail.ru, https://orcid.org/0000-0003-4466-5891

\section{Информация об авторах}

Юрий Анатольевич Прокопенко, доктор исторических наук, доцент, профессор кафедры социальной философии и этнологии, Гуманитарный институт Северо-Кавказского федерального университета, ул. Пушкина, 1, 355009 г. Ставрополь, Российская Федерация, z_proko_15@mail.ru, https://orcid.org/0000-0001-7060-5054

Светлана Леонидовна Кравцова, заведующая кафедрой археологии, Ставропольский государственный историко-культурный и природно-ландшафтный музей-заповедник им. Г.Н. Прозрителева и Г.К. Праве, ул. Дзержинского, 135, 355035 г. Ставрополь, Российская Федерация, vetochkakaleo@mail.ru,https://orcid.org/0000-0003-4466-5891 